\title{
The use of MRI in quantification of the atrial fibrosis in patients with rheumatic mitral disease
}

\author{
Ahmed Shehata Ismail, Yasser Baghdady, Mohammad Ali Salem* (iD and Amir Abdel Wahab
}

\begin{abstract}
Background: Atrial fibrillation (AF) is a common type of arrhythmia with higher incidence in countries with increased prevalence of rheumatic heart disease (RHD), where AF contributes to significant morbidity and mortality in young population. Atrial fibrosis is a common feature of AF. Delayed enhancement MRI (DE-MRI) is a wellestablished method for characterizing fibrosis in ventricles. The use of DE-MRI to detect left atrial fibrosis helps to evaluate the extent of atrial structural remodeling non-invasively. The aim of this study is to evaluate the atrial fibrosis in patients with mitral valve disease, using the DE MRI, regarding its amount, distribution, and relation to AF.

Results: Patients with AF were older and have longer duration of symptoms, smaller valve area, larger LA size, and more fibrosis at the left atrium (with the posterior wall most frequently involved) in comparison to those with sinus rhythm. Patients with atrial fibrosis were older and have longer duration of symptoms, smaller valve area, and larger $L A$, and most of them had AF compared to those without fibrosis. The comparison between types of AF showed a significant difference in the amount of atrial fibrosis that increases across the spectrum of AF.
\end{abstract}

Conclusion: In patients with rheumatic mitral valve diseases, AF is associated with more atrial fibrosis as assessed by DE-MRI. Atrial fibrosis is the best independent predictor of AF.

Keywords: Rheumatic mitral valve disease, AF, Atrial fibrosis, Delayed enhancement MRI

\section{Background}

Atrial fibrillation (AF) is the most common sustained arrhythmia, being present in $0.4 \%$ of the overall population and in $3-5 \%$ of those older than 65 years old [1]. This incidence is higher in countries with a high prevalence of rheumatic heart disease (RHD). In these countries, AF contributes to significant morbidity and mortality in a relatively young population [2].

Atrial fibrosis is a common feature of clinical AF and is associated with AF in a variety of experimental paradigms $[3,4]$. In humans, AF is secondary to underlying organic heart disease in $70 \%$ of patients and lone AF in the rest [5]. Increased collagen deposition has been documented in lone-AF patients compared with sinus rhythm control

\footnotetext{
*Correspondence: masalem55@yahoo.com

Cairo University, Faculty of medicine, Kasr El-Einy st, Cairo, Egypt
}

subjects [6]. Fibrosis is also observed in AF patients with underlying structural heart disease, including mitral valve disease (MVD) and cardiomyopathy [7].

Delayed enhancement MRI (DE-MRI) is a wellestablished, non-invasive method for characterizing fibrosis and tissue remodeling in the ventricle $[8,9]$. Despite its success, however, the use of DE-MRI has been confined largely to the ventricle because of the challenges in the spatial resolution required to image the left atrium (LA) wall. Of note, appropriate imaging methodology allows for successfully obtaining DE-MRI scans with sufficient spatial resolution and signal-to-noise ratio for visualization and analysis of left atrial tissue.

The use of DE-MRI to detect left atrial fibrosis improves the opportunity to evaluate the extent of atrial structural remodeling non-invasively.
SpringerOpen

(c) The Author(s). 2020 Open Access This article is licensed under a Creative Commons Attribution 4.0 International License, which permits use, sharing, adaptation, distribution and reproduction in any medium or format, as long as you give appropriate credit to the original author(s) and the source, provide a link to the Creative Commons licence, and indicate if changes were made. The images or other third party material in this article are included in the article's Creative Commons licence, unless indicated otherwise in a credit line to the material. If material is not included in the article's Creative Commons licence and your intended use is not permitted by statutory regulation or exceeds the permitted use, you will need to obtain permission directly from the copyright holder. To view a copy of this licence, visit http://creativecommons.org/licenses/by/4.0/. 
The aim of this study is to evaluate the atrial fibrosis in patients with mitral valve disease, using the DE MRI, regarding its amount, distribution, and relation to AF.

\section{Methods}

All procedures performed in this study were in accordance with the ethical standards, approved by the ethics committee of our institute, and complied with the Declaration of Helsinki 1964 and its later amendments. Written informed consent was obtained from all individual participants included in this study.

This study recruited prospectively two groups of patients: group A, 30 patients with rheumatic MVD in sinus rhythm, and group B. 30 patients with rheumatic MVD with symptomatic AF.

\section{Exclusion criteria}

1. Mitral valve disease requiring surgery

2. Contra-indications for cardiac MRI

- Metallic medical devices including, e.g., pacemakers or implantable cardioverter-defibrillator (ICD)

- Unstable patients

\section{Study design}

All eligible patients in both groups were subjected to the following:

\section{Clinical assessment}

For each patient, a detailed history, complete physical examination, 12-lead ECG, and routine laboratory tests (including the $\mathrm{CBC}$, liver and renal function tests, and HbA1c) were performed with special emphasis on anthropometric data (age, gender, and body weight), nature and severity of the underlying heart disease, heart rate and rhythm, and systolic and diastolic blood pressures at the time of the study. AF defined as paroxysmal (AF that terminates spontaneously or with intervention within 7 days of onset, episodes may recur with variable frequency), persistent (continuous AF that is sustained $>7$ days), and long-standing persistent (continuous AF of > 12 months duration) according to ACC/AHA/ESC 2014 Guidelines for the Management of Patients with Atrial Fibrillation [10].

\section{Trans-thoracic echocardiographic examination}

For all patients, a comprehensive echocardiographic examination was done in accordance with the recommendations of the American Society of Echocardiography with special empathies on the nature, severity of MVD, any associated valvular lesions, and LA diameter and volume. LA volume was calculated using biplane

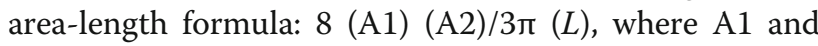
A2 represent the maximal planimetered LA area acquired from the apical 4- and 2-chamber views, respectively, and $L$ is length. The LA long-axis length is determined as the distance of the perpendicular line measured from the middle of the plane of the mitral annulus to the superior aspect of the LA (Fig. 1). The length was measured in both the 4- and 2-chamber
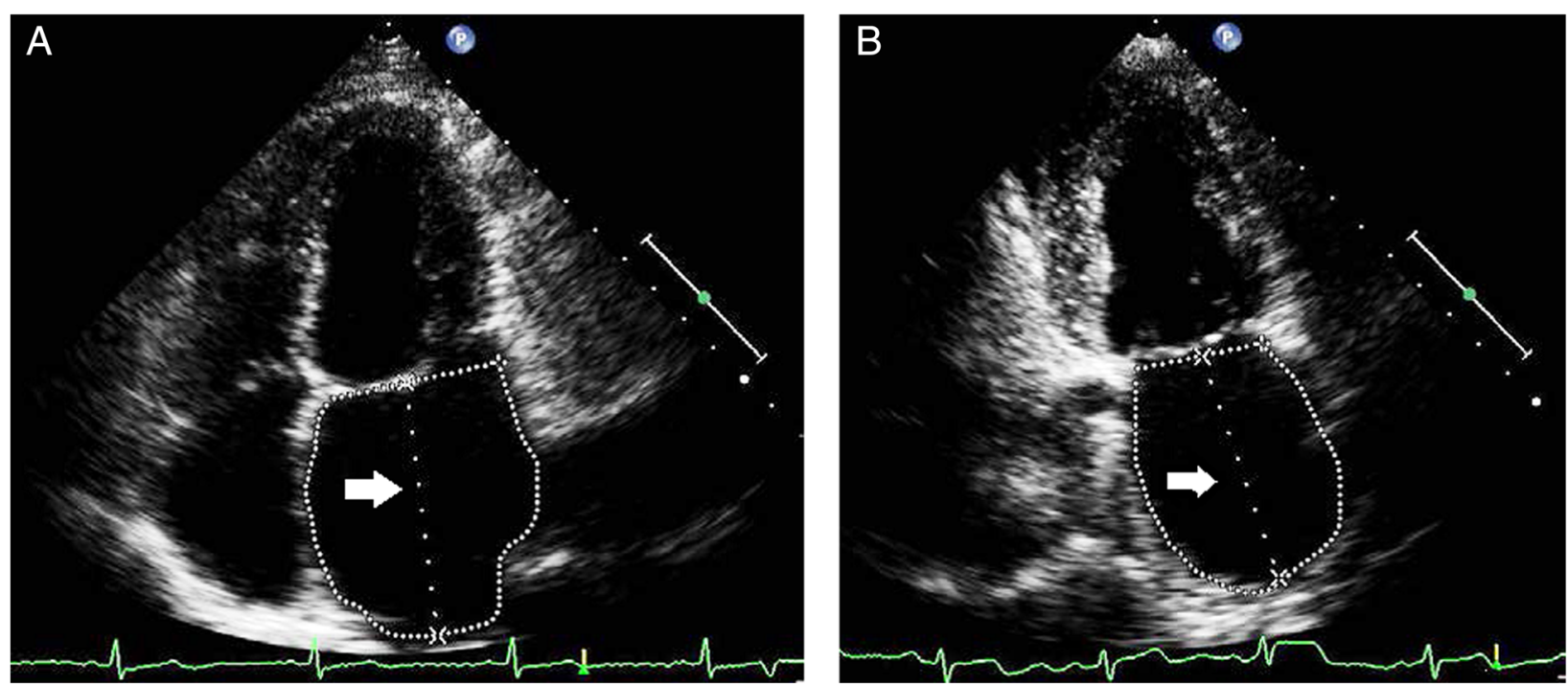

Fig. 1 Measurement of left atrial volume from the area-length method using the apical four-chamber (a) and apical two-chamber (b) views. The length $(L)$ is measured from the back wall to the line across the hinge points of the mitral valve (arrow). The shorter $(L)$ from either the A4C or $\mathrm{A} 2 \mathrm{C}$ is used in the equation 
views and the shortest of these 2 length measurements was used in the formula. Patients were studied in the supine position, and ECG leads were connected to define the timing of cardiac cycle events. This was performed with GE Vivid 5 echocardiographic machine.

\section{Cardiac MRI}

No special instructions were required prior to the examination. Medications are not to be discontinued. Patients were first screened for contraindication to MR imaging. All steps of the study (including the breath-holding instructions) were explained for the patients.

A Philips Achiva, 3 Tesla (Netherland) superconducting magnet was used in a radiology center.

All patients were examined in the supine position, head first.

Four carbon fibers ECG pads were placed on the anterior chest wall. The QRS complex was checked on the MRI monitor; adjustments of the site of the leads was done accordingly.

The SENSE (sensitivity encoding) cardiac coil (6-element phased array coil, receive only) was used. It has a rigid lower part and flexible upper part. The lower part contains two phased array coil elements and the upper part contains four elements. The respiratory sensor was placed over the maximum area of respiratory movement (abdomen or thorax) under the coil.

\section{Cardiac MR protocol}

Scout images were acquired first in orthogonal orientations for planning of the final long-axis and short-axis views.

Standard delayed gadolinium enhancement imaging was acquired about 15 min after the contrast agent injection (dose, $0.1 \mathrm{mmol} / \mathrm{kg}$ body weight; gadopentetate dimeglumine (Magnevist)) using inversion-recoveryprepared, gradient-echo pulse sequence with fat saturation. Short-axis plane and long-axis planes were taken, covering the whole atria, with the following parameters:

\begin{tabular}{ll}
\hline TR/TE: $3.8 / 1.86$ & FOV: 300 \\
TI: $260-350$ & NSA: 1 \\
Matrix, $128 \times 128$ & Bandwidth: $125 \mathrm{kHz}$ \\
Flip angle: $15^{\circ}$ & Scan Time: $9-15 \mathrm{~s}$ \\
Slice thickness: $8 \mathrm{~mm}$ & Slice number: $8-11$ \\
\hline
\end{tabular}

The typical scan time for the DE-MRI study was 5 to 9 min, depending on the subject's respiration and heart rate. All patients underwent the MR examination without complications.

\section{Image analysis}

Images were transferred to a workstation (Brilliance 170 P) equipped with a dedicated cardiac software, for further analysis. Fibrosis was defined as an area of increased signal intensity of the atrial wall relative to the normal myocardium in the late-enhancement images [11]. Fibrosis was assessed in the left and right atria. The LA was divided into three segments (septum, anterior wall, and posterior wall) [7]. The amount of fibrosis was estimated as:

1. Mild; when it involves a segment of a wall, two segments of two walls, or an entire one wall of the atrium (Figs. 2 and 3).

2. Moderate; when it involves one entire wall and a part of another wall, two entire walls, or parts of the three walls (Fig. 4).

3. Severe; when it involves the entire three walls of the LA, circumferential involvement, or both the left atrium (entire three walls) and right atrium [11] (Fig. 5).

\section{Statistical methodology}

Statistical analysis was performed using Statistical Package for Social Sciences, version 16 (SPSS 16). All of the quantitative variables in this research were normally distributed and accordingly are presented as mean $\pm \mathrm{SD}$. Qualitative data are presented as number (percentage).

The comparison between patients with atrial fibrillation and those with sinus rhythm was conducted using Student's $t$ test and chi-square. The correlation was done between the amount of fibrosis and clinical and echocardiographic variables. The probability value of $<0.05$ was considered statistically significant.

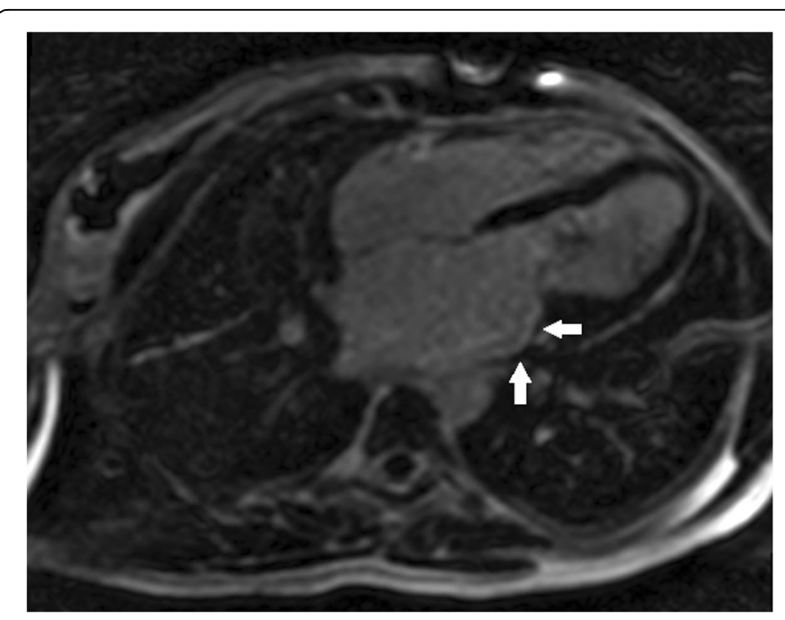

Fig. 2 DE-MRI showing mild atrial fibrosis (involves a part of the posterior wall of the left atrium, arrows) 


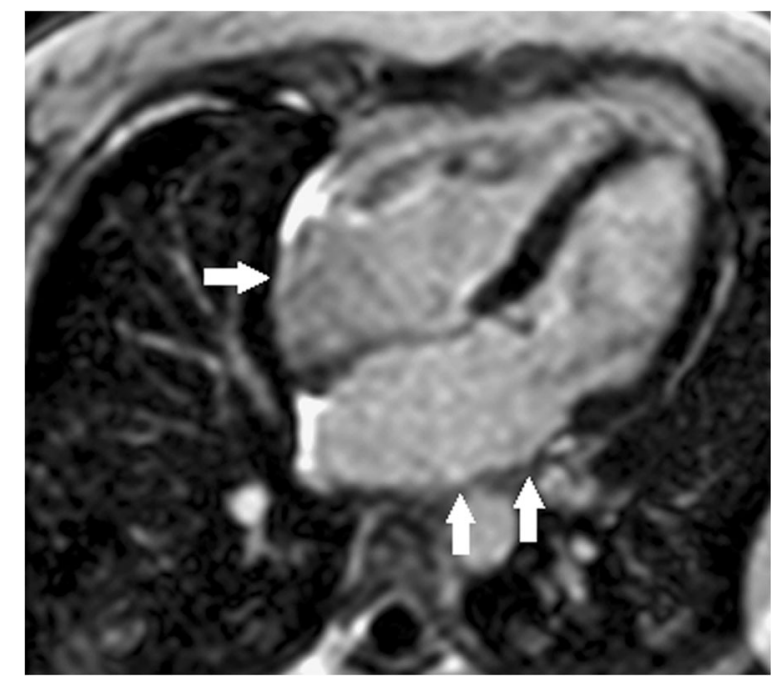

Fig. 3 DE-MRI showing mild atrial fibrosis (involves a part of the posterior wall of the left atrium and a part of the right atrium, arrows)

\section{Results}

A total of 60 patients met eligibility criteria during the study period.

\section{Baseline clinical characteristics}

The mean age was $32.6 \pm 8.2$ years. Thirty-eight (63.3\%) patients were females. Two patients were hypertensive, 5 were diabetic, and one had cerebro-vascular stoke. All patients were symptomatic with dyspnea; most of them NYHA class II (47 patients, 78.3\%). The New York Heart Association (NYHA) Functional Classification provides a simple way of classifying the extent of heart failure. It places patients in one of four categories based on how much they are limited during physical activity. In class I, the ordinary physical activity does not cause undue

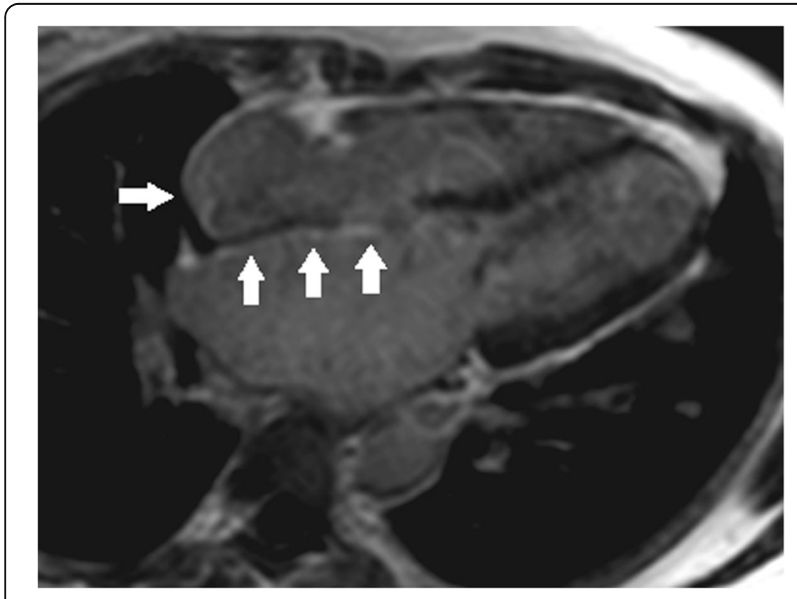

Fig. 4 DE-MRI showing LA enlargement and moderate atrial fibrosis (involves the entire septum and the right atrium, arrows)

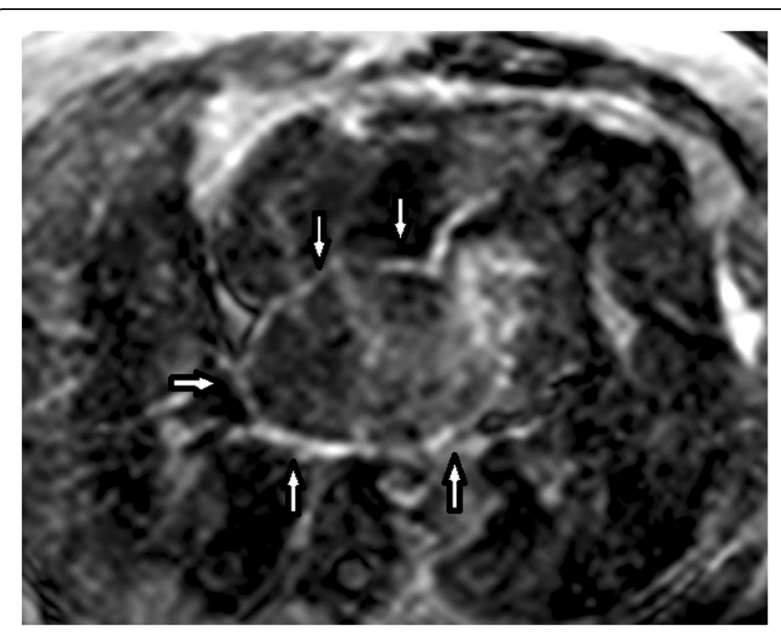

Fig. 5 DE-MRI showing severe left atrial fibrosis (circumferential, arrows)

fatigue, palpitation, and dyspnea. In class II, the patient feels comfortable at rest while the ordinary physical activity results in fatigue, palpitation, and dyspnea. In class III, the patient feels comfortable at rest while the less than ordinary physical activity results in fatigue, palpitation, and dyspnea. In class VI, the patient is unable to carry on any physical activity without discomfort with symptoms of heart failure at rest, and if any physical activity is undertaken, discomfort increases [12].

All patients with AF complained of palpitation with a median duration of 12 months (range 6-48 months). All patients were on beta-blockers and only 7 patients were on amiodarone.

\section{Baseline echocardiographic and MRI characteristics of the patients}

All patients had mitral stenosis; only 10 of them had double MVD. All the ten patients had predominant mitral stenosis and no more than moderate regurgitation. The mitral valve area, the LA diameter, and the atrial volume were evaluated using echocardiography while the amount and distribution of fibrosis were evaluated by the DEMRI (Table 1).

\section{Comparison analysis}

Patients with AF were compared to those in sinus rhythm Patients in AF were older and have longer duration of symptoms, smaller valve area, larger LA size, and more fibrosis, involving the left atrium more than the right one with the posterior left atrial wall most frequently involved (Table 2). 
Table 1 Baseline echocardiographic and MRI data

\begin{tabular}{ll}
\hline Variable & $\begin{array}{l}\text { Mean (SD) } \\
\text { or no (\%) }\end{array}$ \\
\hline Valve lesion & $50(83.3 \%)$ \\
Mitral stenosis & $10(16.7 \%)$ \\
Double mitral valve disease & $1.25 \pm 0.17$ \\
Mitral valve area by echocardiography, $\mathrm{cm}^{2}$ & \\
Atrial dimension & $4.82 \pm 0.51$ \\
LA diameter by echocardiography, cm & $2.62 \pm 0.308$ \\
LA diameter by echocardiography/BSA, cm/m² & \\
Atrial volume & $73.03 \pm 7.73$ \\
LA volume by echocardiography, $\mathrm{ml}$ & $39.75 \pm 4.64$ \\
LA volume index by echocardiography, ml/m² & \\
Amount of fibrosis by DE-MRI & $20(33.3 \%)$ \\
No fibrosis & $13(21.7 \%)$ \\
Mild fibrosis & $12(20 \%)$ \\
Moderate fibrosis & $15(25 \%)$ \\
Severe fibrosis & \\
Distribution of fibrosis by DE-MRI & \\
Left atrium & $25(41 \%)$ \\
$\quad$ Posterior wall &
\end{tabular}

BSA body surface area

Patients with atrial fibrosis were compared to those without atrial fibrosis

Patients with atrial fibrosis were older and have longer duration of symptoms, smaller valve area, and larger LA, and most of them (75\%) had atrial fibrillation (Table 3 ).

\section{Patients were compared according to the type of AF}

The comparison between types of AF showed a significant difference in the amount of atrial fibrosis that increases across the spectrum of AF (more in longstanding persistent AF than persistent AF than paroxysmal AF) with more involvement of the left atrium than the right one. Among the three left atrial walls, the posterior one is the most involved (Table 4).

A one way ANOVA test was conducted to show the differences among types of atrial fibrillation (paroxysmal, persistent, and long-standing persistent). There was significant difference regarding age, duration of symptoms, valve area by echo, LA size by echo, and duration of AF (Table 5).

\section{Regression analysis}

\section{Prediction of atrial fibrillation}

Binary logistic regression was conducted to determine the predictors of AF. The amount of atrial fibrosis
Table 2 Comparison between patients in sinus rhythm and those in $\mathrm{AF}$

\begin{tabular}{|c|c|c|c|}
\hline & $\begin{array}{l}\text { Patients in sinus } \\
\text { rhythm }(n=30)\end{array}$ & $\begin{array}{l}\text { Patients in AF } \\
(n=30)\end{array}$ & $\begin{array}{l}P \\
\text { value }\end{array}$ \\
\hline Age, years & $30.7 \pm 6.98$ & $35.17 \pm 8.76$ & 0.016 \\
\hline Gender, female & $12(54.5 \%)$ & $10(45.5 \%)$ & 0.789 \\
\hline $\mathrm{DM}$ & 0 & $5(16.7 \%)$ & 0.02 \\
\hline HTN & 0 & $2(6.7 \%)$ & 1.154 \\
\hline CVS & 0 & $1(3.3 \%)$ & 0.317 \\
\hline $\begin{array}{l}\text { Duration of symptoms, } \\
\text { months }\end{array}$ & $20 \pm 7.27$ & $31.80 \pm 16.38$ & 0.001 \\
\hline $\begin{array}{l}\text { Mitral valve area by } \\
\text { echo, } \mathrm{cm}^{2}\end{array}$ & $1.33 \pm 0.182$ & $1.17 \pm 0.121$ & $<0.001$ \\
\hline LA diameter by echo, cm & $4.5 \pm 0.335$ & $5.13 \pm 0.469$ & $<0.001$ \\
\hline LA diameter/BSA, cm/m² & $2.46 \pm 0.22$ & $2.78 \pm 0.29$ & $<0.001$ \\
\hline LA volume by echo, ml & $68.20 \pm 6.67$ & $77.87 \pm 5.35$ & $<0.001$ \\
\hline $\begin{array}{l}\text { LA volume index by } \\
\text { echo, } \mathrm{ml} / \mathrm{m}^{2}\end{array}$ & $37.30 \pm 4.28$ & $42.20 \pm 3.62$ & $<0.001$ \\
\hline Presence of fibrosis & $10(33.3 \%)$ & $30(100 \%)$ & $<0.001$ \\
\hline Moderate or severe fibrosis & $6(21 \%)$ & $21(70 \%)$ & $<0.001$ \\
\hline \multicolumn{4}{|l|}{ Distribution of fibrosis } \\
\hline \multicolumn{4}{|l|}{ Left atrial walls involved } \\
\hline Posterior wall & $8(26.7 \%)$ & $26(86.7 \%)$ & $<0.001$ \\
\hline Septum & $1(3.3 \%)$ & $20(66.7 \%)$ & $<0.001$ \\
\hline Anterior wall & $4(14 \%)$ & $14(46.7 \%)$ & 0.005 \\
\hline $\begin{array}{l}\text { Right atrium } \\
\text { involvement }\end{array}$ & $6(20 \%)$ & 19 (63.3\%) & 0.001 \\
\hline
\end{tabular}

DM diabetes mellitus, HTN hypertension, CVS cerebrovascular stroke, BSA body surface area

followed by LA size was the most important predictor of atrial fibrillation.

Stepwise multivariate regression analysis was done to estimate the importance of each variable contribution in the prediction model. Left atrial fibrosis, left atrial volume, and then mitral valve area are the most important predictors of atrial fibrillation in this descending order.

\section{Prediction of atrial fibrosis}

Binary logistic regression was conducted to determine the predictors of atrial fibrosis. Valve area followed by LA size is the most important predictor of atrial fibrosis.

Stepwise multivariate regression analysis was done to estimate the importance of each variable contribution in the prediction model. Valve area, gender, and then symptoms duration are the most important predictors of atrial fibrosis in this descending order.

\section{Prediction of severe atrial fibrosis}

Binary logistic regression was conducted to determine the predictors of severe atrial fibrosis. Left atrial size 
Table 3 Comparison between patients with atrial fibrosis and those without atrial fibrosis

\begin{tabular}{llll}
\hline & Patients with atrial fibrosis $(\boldsymbol{n}=\mathbf{4 0})$ & Patients without atrial fibrosis $(\boldsymbol{n}=\mathbf{2 0})$ & $\boldsymbol{P}$ value \\
\hline Age, year & $34.72 \pm 8.11$ & $28.40 \pm 7.00$ & 0.004 \\
Gender, male & $19(54.5 \%)$ & $3(45.5 \%)$ & 0.014 \\
DM & $5(12.5 \%)$ & 0 & 0.159 \\
HTN & $2(5 \%)$ & 0 & 0.548 \\
CVS & $1(2.5 \%)$ & 0 & 0.99 \\
Duration of symptoms, month & $29.55 \pm 14.90$ & $18.60 \pm 7.76$ & 0.003 \\
Mitral valve area by echo, $\mathrm{cm}^{2}$ & $1.18 \pm 0.162$ & $1.38 \pm 0.116$ & $<0.001$ \\
LA diameter by echo, cm & $4.99 \pm 0.537$ & $4.46 \pm 0.176$ & $<0.001$ \\
LA diameter/BSA, cm/m & $2.71 \pm 0.315$ & $2.40 \pm 0.184$ & $<0.001$ \\
LA volume by echo, $\mathrm{ml}$ & $75.60 \pm 7.45$ & $67.90 \pm 5.45$ & $<0.001$ \\
LA volume index by echo, $\mathrm{ml} / \mathrm{m}^{2}$ & $41.09 \pm 4.37$ & $37.07 \pm 4.04$ & 0.001 \\
Atrial fibrillation & $30(75 \%)$ & 0 & $<0.001$ \\
\hline
\end{tabular}

DM diabetes mellitus, HTN hypertension, CVS cerebrovascular stroke, BSA body surface area

followed by symptoms duration is the most important predictor of severe atrial fibrosis.

Stepwise multivariate regression analysis was done to estimate the importance of each variable contribution in the prediction model. Left atrial diameter followed by symptoms duration is the most important predictor of severe atrial fibrosis.

\section{Discussion}

\section{Atrial fibrosis (amount and distribution)}

Left atrial (LA) late gadolinium enhancement (LGE) on cardiovascular magnetic resonance (CMR) imaging is indicative of fibrosis and has been correlated with reduced LA function, increased LA volume, and poor procedural outcomes in cohorts with atrial fibrillation (AF) [12]. Previous studies had assessed left atrial fibrosis using DE-MRI. However, these studies were done in non-valvular AF patients [7, 11]. To the best of our knowledge, our study is the first one to study atrial fibrosis regarding its amount and distribution in patients with rheumatic MVD using DE-MRI.

\section{Amount of fibrosis}

Among the most consistently described structural abnormalities associated with AF is the development of atrial fibrosis [13]. Atrial fibrosis is the process in which collagen and extracellular matrix are deposited within the atria, often resulting in heterogeneous conduction and impaired contraction. It has been described in a range of conditions including aging $[14,15]$, heart failure $[16,17]$, valve disease [18], hypertension [19, 20], and myocardial infarction (MI) [21].

Table 4 Comparison between patients according to the type of AF regarding demographic data and atrial fibrosis

\begin{tabular}{|c|c|c|c|c|}
\hline & Paroxysmal AF $(n=10)$ & Persistent AF $(n=9)$ & Long-standing persistent AF $(n=11)$ & $P$ value \\
\hline Gender, female & $6(60 \%)$ & $6(66.7 \%)$ & $8(72.7 \%)$ & 0.544 \\
\hline DM & 0 & $2(22.2 \%)$ & $3(27.3 \%)$ & 0.103 \\
\hline HTN & 0 & $1(11.1 \%)$ & $1(9.1 \%)$ & 0.440 \\
\hline CVs & 0 & 0 & $1(3.3 \%)$ & 0.248 \\
\hline \multicolumn{5}{|l|}{ Presence of fibrosis } \\
\hline Mild & $9(90 \%)$ & 0 & 0 & $<0.001$ \\
\hline Moderate & $1(10 \%)$ & $5(55.6 \%)$ & 0 & $<0.001$ \\
\hline Severe & 0 & $4(44.4 \%)$ & $11(100 \%)$ & $<0.001$ \\
\hline \multicolumn{5}{|l|}{ Distribution of fibrosis } \\
\hline \multicolumn{5}{|l|}{ Left atrial walls } \\
\hline Posterior wall & $7(70 \%)$ & $8(88.9 \%)$ & $11(100 \%)$ & 0.048 \\
\hline Septum & $3(30 \%)$ & $6(66.7 \%)$ & $11(100 \%)$ & 0.001 \\
\hline Anterior wall & 0 & $3(33.3 \%)$ & $11(100 \%)$ & $<0.001$ \\
\hline Right atrium involvement & $2(20 \%)$ & $6(66.7 \%)$ & $11(100 \%)$ & $<0.001$ \\
\hline
\end{tabular}


Table 5 Comparison between types of AF regarding demographic and echocardiographic data

\begin{tabular}{lllll}
\hline & Paroxysmal AF $(\boldsymbol{n}=\mathbf{1 0})$ & Persistent AF $(\boldsymbol{n}=\mathbf{9})$ & Long-standing AF $(\boldsymbol{n}=\mathbf{1 1})$ & $\boldsymbol{P}(\mathrm{ANOVA})$ \\
\hline Age, year & $28.82 \pm 5.71$ & $37.56 \pm 7.68$ & $39.0 \pm 9.19$ & 0.012 \\
Duration of symptoms, month & $21 \pm 9.03$ & $33.33 \pm 17.0$ & $39.82 \pm 17.23$ & 0.031 \\
Duration of AF, month & $13.8 \pm 4.94$ & $7.89 \pm 2.02$ & $26.2 \pm 12.02$ & $<0.001$ \\
Valve area by echo, $\mathrm{cm}^{2}$ & $1.24 \pm 0.052$ & $1.17 \pm 0.132$ & $1.10 \pm 0.12$ & 0.024 \\
LA diameter by echo, cm & $4.74 \pm 0.12$ & $5.17 \pm 0.44$ & $5.46 \pm 0.43$ & $<.03 \pm 0.27$ \\
LA diameter/BSA, cm/m ${ }^{2}$ & $2.53 \pm 0.12$ & $2.76 \pm 0.19$ & $81.91 \pm 3.96$ & $<0.001$ \\
LA volume by echo, $\mathrm{ml}$ & $72.5 \pm 1.26$ & $78.89 \pm 4.78$ & $44.08 \pm 3.12$ & $<0.001$ \\
LA volume index, $\mathrm{ml} / \mathrm{m}^{2}$ & $39.48 \pm 1.82$ & $41.21 \pm 3.01$ & & $<0.001$ \\
\hline
\end{tabular}

In our study, the presence of atrial fibrosis was more in patients with AF than those in sinus rhythm. Patients with AF showed more severe fibrosis. The amount of atrial fibrosis increases with age, duration of symptoms, and progression of mitral stenosis and LA enlargement. The burden of atrial fibrosis increases across the spectrum of AF. The amount of atrial fibrosis was the best predictor of AF. Using stepwise multivariate regression analysis, atrial fibrosis is still keeping its statistical significant as the best independent predictor of AF.

Previous studies have observed the association between atrial fibrosis and AF in both animal models $[17,22,23]$ and humans $[24,25]$. However, in general, most of these studies have been performed in vitro or on explanted tissues, with limited clinical application.

Platonov et al. [25] found a twofold to threefold increase in the amount of inflammatory cell count and fibrosis by histopathological examination in a patient with AF compared to a control group. These findings were more prevalent and extensive with permanent compared to paroxysmal AF patients.

Swartz et al. [26] found that atrial fibrosis was more in patients who developed post-operative AF compared to those remaining in the sinus rhythm in patients going for open-heart surgery without prior history of AF.

\section{Distribution of atrial fibrosis}

Among the atrial walls studied (septal, anterior and posterior left atrial walls, and right atrial wall), the posterior left atrial wall is the most frequently affected site in all patients $(56.6 \%)$ and in both sinus and AF subgroups $(26.7 \%$ and $86.7 \%$, respectively). This could be explained to the regional propensities for inflammatory reaction in rheumatic fever (MacCallum patch) [7, 24].

Platonov et al. [25] took atrial tissue samples from different locations: crista terminalis at right atrium lateral wall, Bachmann's bundle, superior portion of the interatrial groove, posterior left atrial wall at superior pulmonary vein level, centrally between pulmonary vein ostia, and at inferior pulmonary veins level. They found that the only site-specific, time-dependent change was in the LA at the level of inferior PV. The explanation was that in addition to the possible regional propensities for fibrotic reaction, the characteristics of cardiac motion may play a role. The fulcrum of atrial movement is the site of attachment of the pericardium around the atriaPV junction and may explain relatively accelerated evidence of tissue damage at some sites more than the others.

Oaks et al. [7] demonstrated that not only the extent but also the locations of LA enhancement appear to be important predictors of ablation success. Patients who suffered recurrent AF showed enhancement in all portions of the LA, whereas patients who responded successfully to ablation showed enhancement limited primarily to the posterior wall and septum.

\section{Atrial fibrosis and atrial fibrillation: a cause and effect relationship?}

Atrial fibrosis and AF have been shown to occur concurrently, but it is unclear whether there is a direct cause and effect relationship or whether these events occur as a consequence of independent pathologic changes in the heart [27].

A number of studies have been performed to establish whether fibrosis always accompanies AF. Clinically, histological analyses of atrial biopsy samples from patients with lone AF revealed that $25 \%$ of these patients exhibited no hallmarks of atrial fibrosis [28]. In human lone AF, it has been shown that long-term assessment of patients diagnosed with AF, which had normal-sized atria upon diagnosis, does lead to structural remodeling of the atria causing atrial enlargement and dilatation over a subsequent period of 20 months [29].

Animal models of chronic atrial fibrosis, which utilized chronic rapid ventricular pacing or over-expression of transforming growth factor- $\beta 1$ (TGF- $\beta 1$ ), have an associated increase in atrial fibrosis with increased AF inducibility $[23,30]$.

In our study, most of the patients $(n=40,66.6 \%)$ showed atrial fibrosis that could be explained by the 
underlying rheumatic MVD (essentially a chronic inflammatory disease). All patients in the AF group showed atrial fibrosis. The presence of atria fibrosis in one-third of the patients in the sinus rhythm group suggests a cause rather than an effect relationship. Furthermore, atrial fibrosis was the best predictor of AF. On the other hand, AF was not a significant predictor of atrial fibrosis. Consistent with these data, ROC analysis showed that atrial fibrosis showed the largest area under the curve $(\mathrm{AUC}=0.9$ ) for prediction of AF with more than mild atrial fibrosis could predict $\mathrm{AF}$ with a sensitivity of $100 \%$ and specificity of $66 \%$. In addition, ROC analysis using left atrial diameter could predict atrial fibrosis at a smaller size than $\mathrm{AF}$ (4.55 vs. 4.65 $\mathrm{cm}$ ) that suggests that atrial fibrosis precedes atrial fibrillation at least in this cohort of patients with rheumatic heart disease. So, we can conclude that atrial fibrosis is the cause of AF in patients with rheumatic MVD.

\section{Relation between atrial size and atrial fibrillation/fibrosis} Left atrial (LA) enlargement has been proposed as a barometer of diastolic burden and a predictor of common cardiovascular outcomes such as atrial fibrillation, stroke, congestive heart failure, and cardiovascular death.

Prospective data from the large population-based studies have established a relationship between M-mode antero-posterior LA diameter and the risk of developing $\mathrm{AF}[31,32]$. In the Framingham study, a 5-mm incremental increase in the antero-posterior LA diameter was associated with a 39\% increased risk for subsequent development of AF [33]. In the Cardiovascular Health Study, subjects in sinus rhythm with an antero-posterior LA diameter $>5.0 \mathrm{~cm}$ had approximately four times the risk of developing AF during the subsequent period of surveillance [32]. LA volume has been shown to predict $\mathrm{AF}$ in patients with cardiomyopathy [34] and first-diagnosed non-valvular AF in a random sample of elderly Olmsted County residents who had undergone investigation with a clinically indicated echocardiogram [35].

In our study, LA size was larger in patients with AF than those in sinus rhythm and the LA size differs significantly across the spectrum of AF.

In our study, minimal increase in LA diameter and size were associated with increased odds of developing $\mathrm{AF}$, as a $1-\mathrm{mm}$ incremental increase in LA diameter was associated with $49 \%$ increase in the odds of developing AF and a 1-ml incremental increase in LA volume was associated with $32 \%$ increase in the odds of developing AF.

LA diameter $\geq 4.65 \mathrm{~cm}$ could predict $\mathrm{AF}$ with a sensitivity and specificity of $80 \%$ and $84 \%$, respectively. LA volume $\geq 72.5 \mathrm{ml}$ could predict AF with a sensitivity and specificity of $83 \%$ and $74 \%$, respectively. This smaller threshold to predict AF compared to the Cardiovascular Health Study [36] could also be explained by the rheumatic etiology of AF.
Knackstedt et al. [37] conducted a study using dogs and induced $\mathrm{CHF}$ using rapid ventricular stimulation followed by rapid atrial stimulation to induce AF. They found that atrial fibrillation/CHF leads to significant atrial fibrosis and dilation. They concluded that increased echocardiographic size correlates to the degree of atrial fibrosis and may be used as a simple clinical marker for atrial fibrosis. The fibrosis accompanying atrial dilatation may also explain why LA size, as determined by echocardiography, is a strong predictor of cardioversion success.

In our study, the LA size was larger in patients with atrial fibrosis than those without atrial fibrosis. Among clinical and echocardiographic variables, LA diameter had the greatest correlation with LA fibrosis $(r=0.74, P$ $<0.001)$. LA diameter $\geq 5.05 \mathrm{~cm}$ can predict severe atrial fibrosis with a sensitivity and specificity of $93 \%$ and $94 \%$, respectively. Taking these data together, we can conclude that LA can be used as a simple marker of atrial fibrosis and may guide the success of AF ablation in patients with rheumatic MVD.

\section{Relation between mitral valve area and atrial fibrillation/ fibrosis}

To the best of our knowledge, our study is the first one to study the relation between mitral valve area and atrial fibrillation/fibrosis using DE MRI.

We found that the mitral valve area was smaller in patients with AF than those in the sinus rhythm. The mitral valve area differs significantly across the spectrum of $\mathrm{AF}$ and could differentiate between the three different types of AF. A 1-mm incremental decrease in mitral valve area is associated with 2.71 times increase in the risk of developing AF.

Mitral valve area $\leq 1.25 \mathrm{~cm}^{2}$ can predict atrial fibrosis with a sensitivity and specificity of $95 \%$ and $73 \%$. The mitral valve area was the best independent predictor for the presence of atrial fibrosis.

\section{Mitral valve area/LA size and atrial fibrosis}

The mitral valve area showed better sensitivity and specificity for the prediction of the presence of atrial fibrosis. On the other hand, LA diameter showed better sensitivity and specificity for the prediction of severe atrial fibrosis.

Taken these data together, we can conclude that mitral valve area is a simple marker for early atrial fibrosis while LA size is a simple marker for severe atrial fibrosis. This could be explained by the natural history of rheumatic MVD where LA enlargement develops secondary to valve distortion and the subsequent progressive hemodynamic load and structural remodeling. 


\section{Conclusion}

- In patients with rheumatic MVD, AF is associated with more atrial fibrosis as assessed by DE-MRI. Posterior left atrial wall is the most frequently affected atrial wall.

- Atrial fibrosis is the best independent predictor of atrial fibrillation and seems to be a cause rather than an effect.

- Mitral valve area is a simple predictor of early fibrosis while LA size is a simple predictor of severe atrial fibrosis.

\section{Limitations}

- The present study is limited by the sample size of 30 patients in the sinus rhythm group and another 30 patients in the AF group, but this was sufficient to draw conclusions.

- Extended Holter monitoring and event monitor were not available to detect asymptomatic AF. However, frequent ECG recording during clinic visits was done.

- We could not segment atrial walls and calculate the relative extent of fibrosis within the LA wall with a threshold-based algorithm. However, defining fibrosis as an area of high signal intensity of the atrial wall relative to the normal myocardium was simple and reproducible.

- The presence of cardiac and respiratory motion artifacts and other MRI noise may lead to the inappropriate detection and quantification of fibrosis, although such effects appeared to be minimal in this study.

\begin{abstract}
Abbreviations
AF: Atrial fibrillation; RHD: Rheumatic heart disease; DE-MRI: Delayed enhancement magnetic resonance imaging; LA: Left atrium; MVD: Mitral valve disease; ICD: Implantable cardio-vascular defibrillator; ECG: Electrocardiogram; ACC: American College of Cardiology; AHA: American Heart Association; ESC: European Society of Cardiology; TR: Time of repetition; TE: Time of echo; FOV: Field of view; NSA: Numbers of signal averages.; NYHA: New York Heart Association; CHF: Congestive heart failure
\end{abstract}

\section{Acknowledgements}

Not applicable

\section{Authors' contributions}

$\mathrm{AS}$, the idea of the study, collected the patients, contributor in writing the manuscript, and was also responsible for data analysis and statistics. YB, performed the echocardiographic studies. MA, performed and interpreted the MR studies. AA, was a major contributor in writing the manuscript. All authors have approved the manuscript for submission.

\section{Funding}

Nothing to be declared

\section{Availability of data and materials}

The datasets used and/or analyzed during the current study are available from the corresponding author on reasonable request.

\section{Ethics approval and consent to participate}

All procedures performed in this study were in accordance with the ethical standards, approved by the ethics committee of Cairo University Hospitals, and complied with the Declaration of Helsinki 1964 and its later amendments. Written informed consent was obtained from all individual participants included in this study.

The ethics committee reference numbers are not available, as the study was started 3 years ago and ended 15 months later, the numbers were not collected at the time of start and could not be reached now.

\section{Consent for publication}

All patients included in this research gave written informed consent to publish the data contained within this study.

\section{Competing interests}

The authors declare that they have no competing interests.

Received: 29 March 2020 Accepted: 21 September 2020

Published online: 30 September 2020

\section{References}

1. Furberg CD, Psaty BM, Manolio TA, Gardin JM, Smith VE, Rautaharju PM (1994) Prevalence of atrial fibrillation in elderly subjects (the Cardiovascular Health Study). Am J Cardiol 74:236-241

2. Roy SB, Bhatia ML, Lazaro EJ, Ramalingaswami V (1963) Juvenile mitral stenosis in India. Lancet 2:1193-1196

3. Kostin S, Klein G, Szalay Z, Hein S, Bauer EP, Schaper J (2002) Structural correlate of atrial fibrillation in human patients. Cardiovasc Res 54(2):361379

4. Li D, Fareh S, Leung TK, Nattel S (1999) Promotion of atrial fibrillation by heart failure in dogs: atrial remodeling of a different sort. Circulation 100(1): $87-95$

5. Levy S (1997) Factors predisposing to the development of atrial fibrillation. Pacing Clin Electrophysiol 20:2670-2674

6. Frustaci A, Chimenti C, Bellocci F, Morgante E, Russo MA, Maseri A (1997) A histological substrate of atrial biopsies in patients with lone atrial fibrillation. Circulation 96:1180-1184

7. Oakes RS, Badger TJ, Kholmovski EG, Akoum N, Burgon NS, Fish EN, Blauer JJ, Rao SN, DiBella EV, Segerson NM, Daccarett M, Windfelder J, McGann CJ, Parker D, MacLeod RS, Marrouche NF (2009) Detection and quantification of left atrial structural remodeling with delayed-enhancement magnetic resonance imaging in patients with atrial fibrillation. Circulation 119(13): 1758-1767

8. Assomull RG, Prasad SK, Lyne J, Smith G, Burman ED, Khan M, Sheppard MN, Poole-Wilson PA, Pennell DJ (2006) Cardiovascular magnetic resonance, fibrosis, and prognosis in dilated cardiomyopathy. J Am Coll Cardiol 48: 1977-1985

9. Bello D, Fieno DS, Kim RJ, Pereles FS, Passman R, Song G, Kadish AH, Goldberger JJ (2005) Infarct morphology identifies patients with substrate for sustained ventricular tachycardia. J Am Coll Cardiol 45:1104-1108

10. Craig T. January, L. Samuel Wann, Joseph S. Alpert, Hugh Calkins, Joaquin E. Cigarroa, Joseph C. Cleveland Jr., Jamie B. Conti, Patrick T. Ellinor, Michael D. Ezekowitz, Michael E. Field, Katherine T. Murray, Ralph L. Sacco, William G. Stevenson, Patrick J. Tchou, Cynthia M. Tracy, Clyde W. Yancy (2014). JACC/ AHA/ ESC 2014 guidelines for the management of patients with atrial fibrillation-executive summary: a report of the American College of Cardiology/American Heart Association Task Force on Practice Guidelines and the Heart Rhythm Society. J Am Coll Cardiol. ;64(21):03-021

11. Casagranda G, Dal Piaz EC, Ravanelli D, Del Greco M, Marini M, Valentini A, Centonze M (2014) Identification of left atrial fibrosis with a lateenhancement MR sequence (LE-MR): preliminary results. Radiol Med 119(8): 595-600

12. Quail M, Grunseich K, Baldassarre LA, Mojibian H, Marieb MA, Cornfeld D, Soufer A, Sinusas AJ, Dana C (2019) Peters Prognostic and functional implications of left atrial late gadolinium enhancement cardiovascular magnetic resonance. J Cardiovasc Magn Reson 21:2

13. Haissaguerre M, Gencel L, Fischer B, Le Métayer P, Poquet F, Marcus Fl, Clémenty J (1994) Successful catheter ablation of atrial fibrillation. J Cardiovasc Electrophysiol 5:1045-1052

14. Gaita F, Riccardi R, Calo L, Scaglione M, Garberoglio L, Antolini R, Kirchner M, Lamberti F, Richiardi E (1998) Atrial mapping and radio frequency ablation 
in patients with idiopathic atrial fibrillation: electrophysiological findings and ablation results. Circulation 97:2136-2145

15. Haissaguerre M, Jais P, Shah DC, Takahashi A, Hocini M, Quiniou G, Garrigue S, Le Mouroux A, Le Métayer P, Clémenty J (1998) Spontaneous initiation of atrial fibrillation by ectopic beats originating in the pulmonary veins. $\mathrm{N}$ Engl J Med 339:659-666

16. Lau CP, Tse HF, Ayers GM (1999) Defibrillation-guided radiofrequency ablation of atrial fibrillation secondary to an atrial focus. J Am Coll Cardiol 33:1217-1226

17. Haissaguerre M, Jais P, Shah DC, Garrigue S, Takahashi A, Lavergne T, Hocini M, Peng JT, Roudaut R, Clémenty J (2000) Electrophysiological end point for catheter ablation of atrial fibrillation initiated from multiple pulmonary venous foci. Circulation 101:1409-1417

18. Chen S, Tai C, Yu W, Chen Y, Tsai C, Hsieh M, Chen C, Prakash V, Ding Y, Chang M (1999) Right atrial focal atrial fibrillation: electrophysiologic characteristics and radiofrequency catheter ablation. J Cardiovasc Electrophysiol 10:328-335

19. Kistler PM, Sanders P, Dodic M, Spence SJ, Samuel CS, Zhao C, Charles JA, Edwards GA, Kalman JM (2006) Atrial electrical and structural abnormalities in an ovine model of chronic blood pressure elevation after prenatal corticosteroid exposure: implications for development of atrial fibrillation. Eur Heart J 27(24):3045-3056

20. Daccarett M, Badger TJ, Akoum N, Burgon NS, Mahnkopf C, Vergara G, Kholmovski E, McGann CJ, Parker D, Brachmann J, Macleod RS, Marrouche NF (2011) Association of left atrial fibrosis detected by delayedenhancement magnetic resonance imaging and the risk of stroke in patients with atrial fibrillation. J Am Coll Cardiol 57(7):831-838

21. Sinno H, Derakhchan K, Libersan D, Merhi Y, Leung TK, Nattel S (2003) Atrial ischemia promotes atrial fibrillation in dogs. Circulation 107(14):1930-1936

22. The Criteria Committee of the New York Heart Association (1994) Nomenclature and criteria for diagnosis of diseases of the heart and great vessels, 9th edn. Little, Brown \& Co, Boston, pp 253-256

23. Ausma J, Wijffels M, Thone F, Wouters L, Allessie M, Borgers M (1997) Structural changes of atrial myocardium due to sustained atrial fibrillation in the goat. Circulation 96(9):3157-3163

24. Verheule S, Sato T, Everett T, Engle SK, Otten D, Rubart-von der Lohe M, Nakajima HO, Nakajima H, Field LJ, Olgin JE (2004) Increased vulnerability to atrial fibrillation in transgenic mice with selective atrial fibrosis caused by overexpression of TGF-beta1. Circ Res 94(11):1458-1465

25. Platonov PG, Mitrofanova LB, Orshanskaya V, Ho SY (2011) Structural abnormalities in atrial walls are associated with presence and persistency of atrial fibrillation but not with age. J Am Coll Cardiol 58(21):2225-2232

26. Burstein B, Nattel S (2008) Atrial fibrosis: mechanisms and clinical relevance in atrial fibrillation. J Am Coll Cardiol 51(8):802-809

27. Swartz MF, Fink GW, Lutz CJ, Taffet SM, Berenfeld O, Vikstrom KL, Kasprowicz K, Bhatta L, Puskas F, Kalifa J, Jalife J (2009) Left versus right atrial difference in dominant frequency, $\mathrm{K}(+)$ channel transcripts, and fibrosis in patients developing atrial fibrillation after cardiac surgery. Heart Rhythm 6(10):14151422

28. Thiedemann KU, Ferrans VJ (1977) Left atrial ultrastructure in mitral valvular disease. Am J Pathol 89:575-604

29. Frustaci A, Chimenti C, Bellocci F, Morgante E, Russo MA, Maseri A (1997) Histological substrate of atrial biopsies in patients with lone atrial fibrillation. Circulation 96:1180-1184

30. Sanfilippo AJ, Abascal VM, Sheehan M, Oertel LB, Harrigan P, Hughes RA, Weyman AE (1990) Atrial enlargement as a consequence of atrial fibrillation. A prospective echocardiographic study. Circulation 82:792-797

31. Vaziri SM, Larson MG, Benjamin EJ, Levy D (1994) Echocardiographic predictors of nonrheumatic atrial fibrillation. The Framingham Heart Study. Circulation 89:724-730

32. Psaty BM, Manolio TA, Kuller LH, Kronmal RA, Cushman M, Fried LP, White R, Furberg CD, Rautaharju PM (1997) Incidence of and risk factors for atrial fibrillation in older adults. Circulation 96:2455-2461

33. Yang SS, Han W, Zhou HY, Dong G, Wang BC, Huo H, Wei N, Cao Y, Zhou G, Xiu CH, Li WM (2008) Effects of spironolactone on electrical and structural remodeling of atrium in congestive heart failure dogs. Chin Med J (Engl) 121:38-42

34. Tani T, Tanabe K, Ono M, Yamaguchi K, Okada M, Sumida T, Konda T, Fujii Y, Kawai J, Yagi T, Sato M, Ibuki M, Katayama M, Tamita K, Yamabe K, Yamamuro A, Nagai K, Shiratori K, Morioka S (2004) Left atrial volume and the risk of paroxysmal atrial fibrillation in patients with hypertrophic cardiomyopathy. J Am Soc Echocardiogr 17:644-648

35. Tsang TS, Barnes ME, Bailey KR, Leibson CL, Montgomery SC, Takemoto Y, Diamond PM, Marra MA, Gersh BJ, Wiebers DO, Petty GW, Seward JB (2001) Left atrial volume: important risk marker of incident atrial fibrillation in 1,655 older men and women. Mayo Clin Proc 76:467-475

36. Abriel H (2010) Cardiac sodium channel $\mathrm{Na}$ (v) 1.5 and interacting proteins: physiology and pathophysiology. J Mol Cell Cardiol 48(1):2-11

37. Knackstedt C, Gramley F, Schimpf T, Mischke K, Zarse M, Plisiene J, Schmid M, Lorenzen J, Frechen D, Neef P, Hanrath P, Kelm M, Schauerte P (2008) Association of echocardiographic atrial size and atrial fibrosis in a sequential model of congestive heart failure and atrial fibrillation. Cardiovasc Pathol 17(5):318-324

\section{Publisher's Note}

Springer Nature remains neutral with regard to jurisdictional claims in published maps and institutional affiliations.

\section{Submit your manuscript to a SpringerOpen ${ }^{\circ}$ journal and benefit from:}

- Convenient online submission

- Rigorous peer review

- Open access: articles freely available online

- High visibility within the field

- Retaining the copyright to your article

Submit your next manuscript at $\boldsymbol{\nabla}$ springeropen.com 